\title{
GÉNESIS DEL ALIENISMO: UNA METÁFORA DE LA LEY. APROXIMACIÓN A EL ALIENISTA DE MACHADO DE ASSÍS
}

\author{
The genesis of alienism: a metaphor of the law. An approach to The \\ Alienist by Machado de Assis
}

María Martínez Díaz*

\begin{abstract}
RESUMEN
En este artículo se elabora una lectura del relato del escritor brasileño Machado de Assis, El alienista. Se propone un primer acercamiento al análisis de este texto literario y de este escritor tan importante y olvidado en la academia costarricense. La lectura versa sobre el tema de la locura, dando luces sobre todo a la institución que ha pretendido dominarla: la psiquiatría. De tal forma, este trabajo reflexionará acerca del surgimiento del alienismo como discurso, como institución y poder que ha construido la figura del alienado, para luego destinarlo al encierro.

Palabras clave: Literatura brasileña, ciencia, psiquiatría, poder, locura.
\end{abstract}

\section{ABSTRACT}

In this paper, it develops a reading of the story El Alienista, from Brazilian writer Machado de Assis. It is proposed an initial approach to the analysis of the literary text and the analysis of this writer who is so important and has been so neglected in the costarican academy. We work around "madness" but specially around psychiatry. The institution that has tried to dominate madness. Thus, we will analysed the emergence of alienism as a discourse, as an institution, and as a power that has been legitimated in the building of the "alienated" figure, to finally shut it.

Key Words: Brazilian Literature, science, psychiatry, power, madness.

Joaquim Maria Machado de Assis (1839-1908), fundador de la primera Academia Brasileña de Letras, y escritor insigne de las letras brasileñas, publica "El alienista" en 1882, texto que encabeza el libro de relatos breves Papéis Avulsos. Se trata de una novela que narra el viaje del protagonista a través de la ciencia y de su poder. Esta es la historia de un psiquiatra, científico y médico: el doctor Simón Bacamarte, quien emprende la aventura quijotesca de descubrir el límite exacto entre la razón y la locura.

\footnotetext{
*Universidad de Costa Rica. Profesora de la Sección de Comunicación y Lenguaje, Escuela de Estudios Generales. Costa Rica. Correo electrónico: mariamartinezdi@gmail.com
}

Recepción: 3/10/2018. Aceptación: 22/01/2019. 
El texto incursiona en lo que el discurso de la ciencia representa en la cultura occidental con respecto a su poder para excluir, invisibilizar y anular al ser humano que no "calce" en lo que ella defina como lo correcto, lo cuerdo o lo sano. En este sentido, Machado de Assis parece deconstruir - de un modo original en el texto- un mundo cientificista a través de un sujeto que encarna el poder de la ciencia: el psiquiatra.

El relato trata de la llegada de Simón Bacamarte a una pequeña ciudad del Estado de Río de Janeiro, en la comarca de Iguaçú: Itaguaí. Ahí, el científico -perteneciente a la nobleza e hijo de médicos- encuentra el lugar en donde se entrega al estudio de la ciencia, que lo llevará posteriormente al de la locura. Cuando su esposa se muestra incapaz de continuar la descendencia de los Bacamarte, el alienista ahoga sus penas en la práctica de la medicina, que lo conduce muy pronto a la psiquiatría: "el recoveco psicológico, el examen de la patología mental” (Machado de Assis, 1974, p. 23). Esto lo lleva a impulsar la construcción de un asilo de locos, que llamará la Casa Verde. Los habitantes de Itaguaí, que empiezan a considerarse enfermos a través del ojo implacable de Bacamarte, pasan a ser diagnosticados y encerrados en esta "casa". Por lo tanto, el problema del encierro es central en la trama del texto y se legitima con la aparición de este actor social, al que el psiquiatra llama "loco(a)": un ser alienado por excelencia, incapaz de retornar a la sanidad, sino es a través de la violencia normativa.

Una reflexión acerca del nacimiento del alienismo se hace necesaria para el análisis de la novela, en vista de que estamos ante un personaje que funda en Brasil precisamente la práctica psiquiátrica, de una forma muy similar a los pioneros de la psiquiatría del siglo XVIII y XIX en Europa. Los mecanismos que el protagonista pone a funcionar, en su interés por apuntalar el saber sobre la locura, tienen que ver con la dinámica dialógica entre lo normativo y lo científico, así como lo social-cultural. 
Por lo tanto, esta lectura busca reflexionar acerca del surgimiento del alienismo como discurso, como institución y poder que ha construido la figura del alienado y luego lo ha destinado al encierro. Para ello se analizará en el texto la antesala del encierro; posteriormente, la imagen del psiquiatra como un nuevo dios, y, por último, el asilo como institución totalitaria.

\section{La antesala del encierro}

El narrador ${ }^{1}$ de este relato -que se puede entender como un Machado de Assis que se autoficcionaliza, que se inventa a sí mismo en el pacto de ficción del texto narrativoenvuelve al lector en una trama que va a mezclar lo relatado a su vez por los cronistas sobre lo que le ocurre a Simón Bacamarte y al pueblo de Itaguaí. Como un Quijote moderno, ${ }^{2}$ el narrador quiere dar fe de la veracidad de su historia al aclarar que ya ha sido contada por los cronistas, ergo, tiene un carácter histórico y, por lo tanto, veraz. Sobra decir, por lo anterior, que es un narrador del cual es necesario desconfiar, pues quiere "engañarnos" y jugar. Al mismo tiempo, estas estrategias suscitan sobre todo una reflexión profunda acerca de los temas que conciernen a este análisis.

Ahora bien, Itaguaí es un pueblito en el que no ocurre gran cosa. Con la llegada de Simón Bacamarte, la transformación del lugar se empieza a estructurar a partir de la construcción de la Casa Verde, el primer hospital psiquiátrico. En esta antesala del encierro, el momento que precede la edificación del hospital, es posible analizar el

\footnotetext{
${ }^{1}$ Es necesario aclarar que el narrador de este relato es particular. Se puede decir que hay aquí un estilo narrativo llamado por Colonna (2004) de autoficción intrusiva. La voz narrativa funciona como disfraz del autor -de ahí que hay quienes le llaman "autor-narrador" o "protagonista-narrador" a la voz narrativa de El alienista-; por lo tanto, podemos ver que se trata de un narrador que juega constantemente con la historia que cuenta: se dedica a hacer comentarios o darle giros irónicos y sarcásticos a lo que acontece. Deja ver a menudo su opinión frente a los acontecimientos y frente a los personajes. Para el análisis del narrador en El alienista, ver trabajos de Bravo (2008), Guedes y Tosta (2003) y Munho (2008).

${ }^{2}$ En El Alienista, hay una marcada presencia (intertexto) del Quijote de Cervantes.
} 
escenario en el que acontece el surgimiento de la psiquiatría: un espacio donde van a enfrentarse instituciones y poderes en torno a la normalidad, que permitirán al final de cuentas la apertura de la institución psiquiátrica, cuyo poder resulta avasallador y trae de la mano la naturalización del encierro y la creación de un nuevo sujeto, el loco.

En Los anormales, Foucault (2007, p. 115) ubica el inicio de la psiquiatría a principios del siglo XIX. Su funcionamiento se percibe como una rama especializada, fundada en una teoría médica. Más aún, se convierte en una rama de la higiene pública. Se institucionaliza a través de su función de protección social frente a los peligros que amenazan el orden. Esta institución médica naciente atiende un problema que la instancia normativa (que incluye el aparato jurídico) ya no puede solucionar: el problema de la locura (Foucault, 2007, p. 39).

El filósofo francés explica que, si partimos de un continuum en la historia, constituido por la "institucionalización de lo represivo y lo punitivo" (Foucault, 2007, p. 41), esta práctica hegemónica se sostiene a través de los discursos de la psiquiatría penal y la práctica de la pericia. Por lo tanto, y como lo explica Robert Castel (2009), cuando se instaura la sociedad burguesa se pone en evidencia una falla en el orden contractual: "el formalismo jurídico no puede controlarlo todo y hay al menos una categoría de individuos que debe ser neutralizada por otras vías de las que dispone el aparato jurídico policial” (p. 42).

En el primer capítulo de la novela, se pueden empezar a explorar los caminos que posibilitan en Itaguaí la creación del primer nosocomio. El hecho de que los "dementes" no recibieran ninguna atención en la Villa antes de la llegada de Bacamarte, viene 
acompañado de una especie de "falta" que conlleva un sentimiento de culpa. ${ }^{3}$ A los ojos del narrador, que se apoya en lo relatado a su vez por los cronistas, esta negligencia es un “pecado” del Ayuntamiento de Itaguaí (Machado de Assis, 1974, p. 25).

El ayuntamiento de Itaguaí, entre otros pecados de que le acusan los cronistas, tenía el de no hacer caso de los dementes. Así es que cada loco furioso era encerrado en una habitación, en su misma casa, y no era curado, sino "descurado", hasta que la muerte le venía a robar el beneficio de la vida; los mansos andaban sueltos por la calle. Simón Bacamarte intentó inmediatamente reformar tan ruin costumbre (Machado de Assis, 1974, pp. 25-26).

El narrador, con su característica mordacidad, quiere evidenciar esta "falta" de la instancia normativa frente a la locura. ${ }^{4}$ El uso de la palabra "pecado" conlleva, además, una carga moral fuerte en este pueblo religioso y devoto a la Iglesia católica. ${ }^{5}$ Implica, asimismo, que hay una injusticia moral que se está haciendo en contra de los locos.

No haberlos atendido, o más bien haberlos dejado libres en su locura se empieza a percibir como un acto inhumano y, al mismo tiempo, se va construyendo a este sujeto,

\footnotetext{
${ }^{3}$ Foucault explica que la locura aparece en la conciencia del hombre occidental de forma diversa, pues coincide con muchos procesos que van transformándola (1972, p. 215). Por ello, no es posible captar el sentido de la locura de un momento histórico determinado, en una sola unidad, su presencia es desmembrada. Según el filósofo, hay cuatro conciencias de la locura, y se pueden entender como estrategias de la razón para "aprehender concretamente la locura, al mismo tiempo que se precave de ella" (Gros, 2000, p. 35). El hecho de que el narrador indique que antes de la llegada de Bacamarte ya había personas declaradas como dementes, sugiere una conciencia de la locura práctica que, de acuerdo con Michel Foucault, separa la locura a partir de las normas del grupo, los que están dentro del grupo deciden quiénes están fuera de él (1972, p. 217). Esta conciencia teme la locura, la reconoce, pero es una conciencia que no se fundamenta en el saber de la ciencia, como lo hará Bacamarte. Es la conciencia analítica, representada en Bacamarte, la que cierra el diálogo con la locura, en la medida en que se dedica a dominarla a través de la "técnica de supresión" (Foucault, 1972, p. 221).

${ }^{4} \mathrm{El}$ ayuntamiento es el lugar en donde el alcalde y los concejales administran los intereses de un municipio (DRAE). Se trata de un espacio en donde se toman decisiones políticas para la administración del municipio. Aunque generalmente el ayuntamiento tiene un poder limitado, al tener que encargarse de territorios pequeños, en el relato, el ayuntamiento representa el poder máximo ocupado de controlar las normas que controlan a la población. Por eso, se le ha llamado aquí instancia normativa.

${ }^{5}$ La presencia y el protagonismo del padre Lopes es fuerte en el pueblo, señal de que hay una Iglesia católica que goza de poder.
} 
antes ignorado y desapercibido, como un ser que debe ser atendido y cuidado. Con esta medida se hace alusión a su estado de fragilidad: se trata de un ser que provoca sentimientos piadosos.

Tal como lo explica Castel (2009), la laguna de la institución jurídica es aplacada por un nuevo dispositivo ${ }^{6}$ más flexible, que podrá resolver el problema de la locura. Supone un problema, pues la justicia no logra controlarla técnicamente. Se le va de las manos y así se ve en la obligación de apelar a otra instancia: la médica, que ante la dureza de la institución judicial y de su administración, se muestra capaz de “desarrollar un modelo de ejercicio del poder alternativo al de la autoridad coercitiva" (Castel, 2009, p. 42). La psiquiatría le va a facilitar los ingredientes esenciales para mantener el orden. Por eso Castel insiste en que la medicina mental nace "a la sombra del legalismo":

En un principio se nutrió de sus contradicciones, para conquistar luego su propio espacio de intervención. Luego fue desarrollándose mientras se mantenía una relación aparentemente polémica con la justicia, pero de hecho dialéctica. El inestable equilibrio entre las dos instituciones conspira con la realización de un mismo fin. Trátese de justicia o de medicina, la cuestión siempre es el orden mismo. Una impone su pervivencia inscribiendo dicho orden en la objetividad de las leyes y combatiendo las transgresiones con sanciones. La otra detecta en cada sujeto una distancia respecto de sus normas e intenta anularla mediante remedios (Castel, 2009, p. 43).

\footnotetext{
${ }^{6}$ El nuevo dispositivo al que se refiere Castel es el de la instancia médica: "La importancia crucial de la cuestión de la locura en el momento de la instauración de la sociedad burguesa se debe, en primer lugar, a que reveló concretamente una laguna del orden contractual: el formalismo jurídico no puede controlarlo todo y hay al menos una categoría de individuos que debe ser neutralizada por otras vías de las que dispone el aparato jurídico judicial. Pero se debe también a que el nuevo dispositivo desplegado para suplir sus carencias va a desarrollar un nuevo modelo de manipulación de plasticidad cuasi-infinita. La mayoría de las nuevas modalidades de control, de las nuevas técnicas de sujeción, de las nuevas relaciones de tutelarización, van a ser médicamente (luego médico-psicológicamente, médicopsicoanalíticamente, etc.) indexadas" (Castel, 2009, p. 42).
} 
En el relato, la primera exposición de la situación de los locos en Itaguaí demuestra que la institución jurídica, mencionada por Castel -representada por el Ayuntamiento ${ }^{7}$ en el relato-, es incompetente para manejarlos. Más aún, es injusta y cruel, al cometer el "pecado" de no ofrecerles su ayuda y compasión. Al mismo tiempo, queda demostrado que estos locos merecen a su vez piedad, por ser seres que sufren una enfermedad. En consecuencia, se prepara el terreno para el advenimiento de la psiquiatría, que se mostrará -al contrario del Ayuntamiento- misericordiosa, piadosa y benevolente.

Para que la psiquiatría se establezca como saber médico tuvo que realizar dos codificaciones. La primera fue catalogar la locura como enfermedad, ${ }^{8}$ y la segunda, considerarla como un peligro. ${ }^{9}$ Así se reafirma como agente de higiene social y, al mismo tiempo, se construye como un saber de la enfermedad mental (Foucault, 2007, p. 116). Si bien, como lo indica Castel, el dispositivo de la instancia médica surge para llenar un vacío de la instancia jurídica, en El alienista es posible percibir la lucha que se libra entre ambas instituciones, representadas por el alienista (instancia médica) y el Ayuntamiento (instancia jurídica). De tal forma, al principio, la instancia normativa (una forma más amplia de referirse a la instancia jurídica) se resiste a reconocer que necesita de la instancia médica para resolver este nuevo problema que se crea en torno

\footnotetext{
${ }^{7}$ El Ayuntamiento se presenta en el relato como la única institución encargada del ordenamiento jurídico, es decir, de dictar las normas que rigen la sociedad de Itaguaí. Castel señala que a finales del siglo XVIII, en Francia, una de las vías del ordenamiento jurídico para controlar la locura era "reenviar a la familia la responsabilidad del control de los actos de los insensatos" (Castel, 2009, p. 40). Tal medida histórica, analizada por Castel, es la que parece dibujarse en el relato de Machado de Assis.

${ }^{8}$ Para lograrlo debió "patologizar los desórdenes, los errores, las ilusiones de la locura" (Foucault, 2007, p. 115). La función de agente de higiene social se fue así acercando al saber médico a través del uso necesario de la sintomatología, las nosografías, los historiales clínicos, etc. Los mismos procedimientos médicos que le permitieron patologizar la locura y así convertirla en enfermedad.

${ }^{9}$ Para la segunda codificación, además de convertir la locura en enfermedad, tuvo que hacerla aparecer como un elemento perturbador: "como portadora de cierto número de peligros" (Foucault, 2007, p. 116), así como de riesgos. En esta medida, la psiquiatría se sigue reafirmando como una institución que "limpia" a la sociedad (higiene pública).
} 
al loco. El alienista, a su vez, lucha por la naturalización del encierro y propone la construcción de la Casa Verde:

La propuesta excitó la curiosidad de toda la villa y encontró gran resistencia, poniendo de manifiesto lo difícil que es desarraigar costumbres absurdas o incluso malas. La idea de meter a los locos en la misma casa, viviendo en común, pareció en sí misma un síntoma de demencia y no faltó quien lo insinuara a la misma mujer del médico (Machado de Assis, 1974, p. 26).

La voz narrativa tiene un tono irónico: esas costumbres "absurdas" y "malas", por el tono del relato, más bien parecieran ser lo contrario. En el fondo, el narrador-autor se manifiesta ideológicamente en contra del alienismo. ${ }^{10} \mathrm{Su}$ voz pervierte el valor de la institución psiquiátrica, lo que muestra la crítica que el texto literario hace sobre la psiquiatría.

La resistencia que enfrenta Bacamarte viene del Ayuntamiento, con la ayuda del padre Lopes ${ }^{11}$ y del resto de habitantes. En Itaguaí -al menos al principio- no parece haber conciencia de que la instancia normativa no puede controlarlo todo. Más bien se defiende su supuesta "negligencia" o "falta" frente a la forma de tratar a los locos, pues se ve como "normal", de ahí que el deseo de Bacamarte de encerrarlos se convierte irónicamente en "anormalidad", en locura. Sin embargo, ante esta reacción, el alienista no duda de que va a convencer al Ayuntamiento de lo contrario.

\footnotetext{
${ }^{10}$ Esta intervención narrativa en el relato se acerca a la función ideológica propuesta por Genette (1972), en la cual hay un cruce entre el autor y el narrador.

${ }^{11}$ El padre Lopes se encarga de insinuarle a doña Evarista (la esposa de Simón Bacamarte), la demencia de su marido.
} 
La voz narrativa se expresa algunas veces a través de una focalización interna: ${ }^{12}$ parece reproducir el pensamiento de un personaje. Sin embargo, este mecanismo ridiculiza esa voz o ese pensamiento, expresando así la función ideológica del narrador. Por ejemplo, cuando el narrador nos cuenta sobre la negligencia del Ayuntamiento frente a los locos, a través de su mirada conocemos de qué forma Bacamarte percibía esta problemática. Con esta medida, el narrador juega un doble rol. Por un lado, focaliza el sentimiento del personaje y, por otro lado, se burla de él: "Simón Bacamarte intentó inmediatamente reformar tan ruin costumbre" (Machado de Assis, 1974, p. 26).

El irónico calificativo "ruin" es el que resume el sentimiento del alienista ante ese abandono de los locos. Esto deja ver su posición frente a la instancia normativa. Su opinión parece clara y contundente: este personaje no duda de su verdad y luchará por imponerla en el Ayuntamiento.

En un primer momento, Bacamarte debe ganar el favor de los concejales, para que posibiliten desde lo normativo la creación de un lugar donde se encierren a los locos. Su instrumento de convencimiento es el discurso:

De allí se fue al Ayuntamiento donde los concejales debatían la propuesta, y la defendió con tanta elocuencia que por mayoría se decidió concederle lo que había pedido, votando al mismo tiempo un impuesto destinado a subvencionar el tratamiento, alojamiento y manutención de los locos pobres (Machado de Assís, 1974, p. 27).

\footnotetext{
${ }^{12}$ La definición de focalización que ofrece Mieke Bal (1998) -concepto derivado de la fotografía y del cine-, se entiende aquí como "la relación entre la visión y lo que se 've', lo que se percibe" (p. 108). Por lo tanto, la focalización permite distinguir entre "la visión a través de la cual se presentan los elementos por una parte, y la identificación del cuerpo/grupo que verbaliza esa visión por la otra", es decir, distingue entre "los que ven y los que hablan" (p. 108). En el análisis del relato, es necesario hablar de una focalización externa, pues se trata de la voz narrativa -agente externo a la historia- la que hace la focalización.
} 
Ahora bien, lo único que sabemos de ese discurso de Bacamarte en el relato es su “elocuencia". En efecto, ya anteriormente ha dado a entender, a través del narrador, que el hecho de ignorar a los locos es una costumbre "ruin"; por lo tanto, en este discurso, que pronuncia frente a los concejales, va entonces a demostrar que la medicina mental es la que solucionará esta falta.

Su manejo del discurso parece ser exitoso, pues la mayoría de los concejales decide favorecerlo inmediatamente. Se puede concluir que su argumentación gira en torno a la utilidad de la medicina mental, pues hay un concejal que lo sigue confrontando y expresa su desaprobación cuando dice: “el Dr. Bacamarte no soluciona nada. ¿Dónde se ha visto meter a todos los locos dentro de la misma casa?" (Machado de Assis, 1974, p. 27; subrayado propio).

Sin embargo, pareciera que frente al alienista, la elocuencia de este concejal se queda muy corta. El narrador sintetiza: “Se engañaba el digno magistrado; el médico lo arregló todo" (Machado de Assis, 1974, p. 27). Aquí se enfrentan de manera clara las dos instancias: la normativa, representada por el magistrado, frente a la médica, representada por el alienista, quien sale victorioso.

La voz narrativa interviene para ofrecer una síntesis del enfrentamiento. Si el magistrado "se engañaba", estaba evidentemente equivocado y perdido, frente a la razón de la instancia médica, que siguen el resto de los concejales. El comentario del narrador es dúctil con el concejal disidente: lo retrata como una persona ingenua que se niega a ver la "verdad", la del hombre de ciencia.

De tal forma, se puede ver más de cerca la propuesta de Robert Castel: este alienista, pionero de la psiquiatría, se nutre de las contradicciones de la instancia normativa, 
reflejadas en su carácter manipulable, conquistado fácilmente por su elocuencia, más aún, por su manejo político. Luego, tal como lo indica Castel, conquista "su propio espacio de intervención” (2009, p. 43) al demostrar que la instancia normativa no puede solucionar el problema de la locura, que la médica sí es capaz de sobrellevar.

Simón Bacamarte triunfa. El pueblo, que antes se burlaba de su empresa, ahora se une a la celebración de la inauguración de la Casa Verde. Lo que antes era percibido como locura, ahora es motivo de encomio. Bacamarte logra convencer a los habitantes de Itaguaí de la nueva "verdad" sobre la locura: es una enfermedad y, por lo tanto, su lamentable estado debe atenderse y, sobre todo, aislarse. Esta tarea monumental de atender la locura se va a convertir a su vez en un acto paternalista y benevolente: "Muchos dementes estaban ya recogidos, y los parientes tuvieron ocasión de ver el cariño paternal y la caridad cristiana con los que iban a ser tratados" (Machado de Assis, 1974, p. 28).

En efecto, Robert Castel (2009, p. 36) explica que para las sociedades de finales del siglo XVIII y principios del siglo XIX, el loco provoca sentimientos ambivalentes de horror y de piedad. Ante esta contradicción, la naciente psiquiatría juega "la carta de la benevolencia”. De esta forma será capaz de controlar este foco de peligro: el loco que no puede ser controlado por la institución jurídica será atendido por la supuesta filantropía de la psiquiatría. Lo importante aquí, en el razonamiento de Castel, es que si bien la medicina mental se viste de un humanismo filantrópico, este no es más que "un auxiliar del juridicismo" (2009, p. 36): cuando lo judicial choca con pared, la psiquiatría viene a ofrecerle una salida. Es decir, aunque la psiquiatría parezca desinteresada, compasiva y piadosa, en realidad su objetivo sigue siendo el mismo de la institución judicial. Su función es la de controlar la locura, por ser foco de desorden social. 
Para el movimiento alienista, hay que ser compasivos con los locos, quienes "lejos de ser culpables que hay que castigar, son enfermos cuyo lamentable estado merece todos los respetos debidos a la humanidad sufriente y se debe procurar devolverles la razón con los medios más sencillos" (Pinel, 1809, citado en Castel, 2009, p. 36). De tal forma, la actitud filantrópica y paternalista ha sido una constante en el alienismo desde su nacimiento. Al mismo tiempo, está "esclarecida por el saber" y se va a desarrollar "en una relación institucional de dominación" (Castel, 2009, p. 36). Además, como se ha venido argumentando, viene a solventar una limitación de la instancia normativa. Frente a las conciencias sociales de Itaguaí, confluyen en el alienismo naciente la caridad y la racionalidad de la ciencia. Se crea una nueva sensibilidad frente al dolor humano. ${ }^{13}$ Todo esto se vuelve más evidente cuando Bacamarte le revela a Crispín Soares "el misterio de su corazón":

La caridad, Sr. Soares, entra ciertamente en mi procedimiento, pero entra como condimento, como la sal de las cosas, porque es así como interpreto lo dicho por San Pablo a los Corintios: "si yo conozco cuanto se puede saber, y no tengo caridad, no soy nada" (Machado de Assis, 1974, p. 31).

Como lo indica Castel, el alienismo triunfa, pues entronca, por un lado, con el saber científico y su respetabilidad y, por otro lado, con la función filantrópica (2009, p. 79). En esta cita es posible ver que la caridad se convierte en un medio y no en el fin. Es, sin embargo, "condimento" lo que le da "sabor" o "gusto" a lo que hace.

Luego la diégesis revela que no es tanta la caridad como el "interés científico" lo que mueve al alienista (Machado de Assis, 1974, p. 35). Y este pasa por el deseo de

\footnotetext{
${ }^{13}$ A propósito, ver el trabajo de Mercedes Flores González: "Mediante el humanitarismo y la ingeniería social, dicha sensibilidad sería encauzada como 'política de la decencia' que invocaba la generosidad hacia los inferiores y el tratamiento civilizado hacia las mujeres, niños, sirvientes y criminales" (2007, p. 30).
} 
controlar la locura, fijarla, clasificarla y, así, anularla para encontrar "su remedio universal”. El alienista se percibe a sí mismo como un nuevo dios.

\section{El psiquiatra: un nuevo dios}

Desde la reflexión de Castel, la compasión de la psiquiatría naciente solo es una fachada, pues ella no es más que un "suplente" o "metáfora" de la ley (2009, p. 37). De tal forma, la violencia que se ejerce dentro de la institución psiquiátrica se justifica en nombre del mejoramiento del paciente: se despliega "por el bien de los sometidos" (Castel, 2009, p. 37). En esta lógica, que se podría llamar también paternalista, se reactiva un discurso "parento-pueril, parento-infantil" que permitirá precisamente la alianza del aparato médico con el normativo. ${ }^{14}$ Esta situación contribuye también al triunfo histórico del alienismo, en este período posrevolucionario, que está en la búsqueda de "nuevas técnicas asistenciales" (Castel, 2009, p. 79).

En el relato, la Casa Verde se inaugura en la "calle más bonita de Itaguaí” (Machado de Assis, 1974, p. 28) lo que merece pomposas ceremonias que se extienden durante siete días. Tal como la creación del mundo en el Génesis, con la Casa Verde se crea un nuevo universo. En él empiezan a reinar el orden y la disciplina, pues lo primero que hace Bacamarte una vez al mando de su nuevo mundo es "organizar" (Machado de Assis, 1974, p. 35). Como resultado, le dice al cura: "La Casa Verde (...) es ahora una especie de mundo, en el que hay un gobierno temporal y un gobierno espiritual" (Machado de Assis, 1974, p. 35; la cursiva es del original).

\footnotetext{
${ }^{14}$ Se trata de un discurso análogo al que usa un padre que se dirige a su hijo con el fin de moralizarlo. Para Foucault, tal discurso gira en torno al campo de la "perversidad" y al "problema del peligro social: vale decir que será igualmente el discurso del miedo y un discurso de moralización, un discurso infantil, cuya organización no puede sino ser irrisoria, aun con respecto a la locura” (Foucault, 2007, p. 43).
} 
En esta metáfora casa verde/mundo, el nosocomio es un nuevo universo en el que también se dividen los poderes. El orden invade todo para que esto sea posible; de ahí la necesidad de clasificar. Hay entonces dos poderes: el temporal y el espiritual, que expresan a su vez conflictos. El primero alude a lo terrenal, perecedero y humano. Es, tal vez, el gobierno de las instancias normativas, en vista de que ellas están presentes en el ordenamiento de este "nuevo mundo". Por este motivo, Bacamarte encarga la ejecución de un "reglamento", que ha sido previamente aprobado por el Ayuntamiento (Machado de Assis, 1974, p. 35).

El segundo gobierno es el del espíritu, el orden de lo eterno y divino. En efecto, este enunciado del alienista recuerda lo que dice Jesús en Mateo 22, 15-21: "Den al César lo que es del César, y a Dios, lo que es de Dios". Esta es una frase que invita a recordar que Dios está por encima de todo y que los gobernantes, si bien tienen su poder, son también instrumentos de Dios. Jesús legitima la autoridad política y le otorga un campo propio del orden y del bien público. Sin embargo, es derivada de Dios y se deben respetar sus leyes. El gobierno temporal no puede exigir la sumisión completa, pues solo Dios tiene ese privilegio.

En el relato, Bacamarte quiere expresar de una forma astuta que él es el representante del gobierno espiritual, mas no en nombre del dios cristiano, sino solo en nombre del dios de la ciencia. En este sentido, si bien Bacamarte reconoce la presencia del "gobierno temporal" -el del Ayuntamiento- se jacta de ser él mismo el representante del poder superior, divino, imperecedero, pero, sobre todo, que está por encima del otro poder -el perecedero y humano, el de las instancias normativas- y puede exigir su sumisión. 
Al mismo tiempo, tanto el gobierno temporal de las instancias normativas como el gobierno espiritual del dios de la ciencia son, a su vez, instituciones jerarquizadas y estructuradas. Ambas tienen un fin común: controlar la locura. Sin embargo, en esta aclaración del alienista ya se expresa una tensión, pues dar lugar a lo que le corresponde a cada gobierno produce cierto desequilibrio. Se puede percibir incomodidad en la respuesta del padre Lopes, quien quiere ver como una broma la osadía de Bacamarte, pero, en el fondo, se podría interpretar su broma como un enunciado literal: "El Padre Lopes se reía de este retruécano y añadía (con el único fin de decir también una chanza):

-Descuide, descuide, que he de mandarle denunciar al Papa" (Machado de Assis, 1974, p. 35). El tono del narrador es irónico y, por lo tanto, se entiende que el objetivo del padre no es solo el que el narrador indica entre paréntesis: "decir una chanza", sino que es también amenazar. Se expresa, así, un enfrentamiento de poderes: el normativo (jurídico), el científico y el religioso. El dios de la ciencia empieza a aplastar a los demás.

De tal forma, en este "nuevo mundo" del nosocomio ya no se busca la salvación del alma, sino la salvación de la cordura, que se debe alcanzar eliminando la locura. En Itaguaí, en la Casa Verde, la medicina mental toma otro matiz: ya no es solo auxiliar de la instancia normativa (jurídica), como lo expresa Castel, sino que está por encima de ella. Es más poderosa, más pertinente, más sagrada, aunque al final haya connivencia entre ambas y su objetivo sea el mismo: el orden, la razón.

\section{Casa Verde e institución totalitaria}

Este nuevo poder de la ciencia, que opaca a la instancia normativa, se va a convertir en una especie de tiranía que llevará al pueblo de Itaguaí a una verdadera revolución. El 
poder institucional del Ayuntamiento se pliega ante la institución psiquiátrica y, luego, el poder de la Iglesia va achicándose paulatinamente. Sin embargo, esto no ocurre de manera pacífica. Poco a poco, el mismo pueblo empieza a sentirse amenazado y violentado ante el poder absoluto que adquiere el alienista.

Como lo han estudiado otros académicos, se puede establecer una comparación entre Simón Bacamarte y Pinel. ${ }^{15}$ El vasto trabajo clasificatorio del alienista de Machado de Assis recuerda la producción teórica pineliana, calco de la medicina del siglo XVIII, cuyo método clasificatorio es heredado "a su vez de las ciencias naturales" (Castel, 2009, pp. 83-84).

Bacamarte divide a sus locos en clases y subclases, pues quiere ordenar los padecimientos mentales, y así crear nosografías. En su trabajo, no hay interés en buscar el origen de la locura o comprenderla a partir del organismo humano, sino que se limita a la experiencia, tal como lo hace Pinel:

Los dividió primeramente en dos clases principales: los furiosos y los mansos; de aquí pasó a las subclases: monomanías, delirios, alucinaciones diversas. Hecho esto, empezó un estudio intenso y continuado; analizaba los hábitos de cada loco, las horas de acceso, las aversiones, las simpatías, las palabras, los gestos, las tendencias; inquiría sobre la vida de los enfermos, profesión, costumbres, circunstancias de la revelación mórbida, accidentes de la infancia y de la adolescencia, enfermedades de otra clase, antecedentes en la familia; una

\footnotetext{
${ }^{15}$ En el movimiento alienista, Phillipe Pinel (1745-1826) marcó un hito: representa el nacimiento de una nueva especialidad de la medicina. Pinel es conocido sobre todo como médico enciclopedista, pero dedica su construcción teórica y práctica a los enfermos mentales en Bicêtre y luego en Salpêtrière. Él es el primero en formular un corpus teórico de la ciencia alienista y crear una tecnología en la práctica hospitalaria, conocida como la "tecnología pineliana". Según Castel, su producción teórica es una continuación de la medicina del siglo XVIII (2009, p. 83). Para ampliar sobre esta relación entre Bacamarte y Pinel, ver trabajos de Oliveira (2006) y Muhno (2008).
} 
investigación, en fin, como no la haría el más concienzudo corregidor (Machado de Assis, 1974, pp. 35-36).

Este camino que toma para estudiar la locura es el que resume la posición hegemónica de la medicina mental desde su nacimiento y que se aboca, en consecuencia, a realizar tratamientos morales que buscan actuar en las causas, las cuales son, a su vez, morales (Castel, 2009, p. 87). Tal actitud frente a la enfermedad es incluso sugerida por la voz narrativa, que compara el trabajo del alienista con el de un "concienzudo corregidor". De esta forma, alude al comportamiento moral de la ciencia frente a la enfermedad: el psiquiatra se comporta como un "magistrado" encargado de juzgar y de castigar los delitos.

En la cita anterior es posible ver una especie de reforma o tecnología pineliana, cuyo principio radica en señalar que el orden permite reprimir cualquier atisbo de rebeldía ante el poder psiquiátrico. Efectivamente, en la cita está retratada una mirada clínica que abarca todo: los alienados están absolutamente controlados y sujetados. El orden que Simón Bacamarte establece en la Casa Verde le permite controlarlos desde la "conformidad de gustos e inclinaciones", hasta su "estado de calma o de efervescencia" (Castel, 2009, p. 70). Se trata de un "orden disciplinario""16 que supone perfección en cuanto al orden que atraviesa los cuerpos -tal como lo vemos en la cita mencionadagracias a la disciplina que penetra en ellos.

Ahora bien, el control que ejerce el alienista sobre la población de la Casa Verde rápidamente se expande al resto de la población de Itaguaí. Se establece así una relación

\footnotetext{
${ }^{16}$ En Le pouvoir psychiatrique (2003), Michel Foucault va a facilitarnos una serie de categorías que nos permiten entender el funcionamiento del asilo. La condición necesaria para el saber médico y para el funcionamiento del asilo es la disciplina. Esta va a constituir lo que él llama el orden disciplinario, que será también la condición para la cura permanente del alienado. Esta disciplina supone un orden perpetuo basado en la regulación permanente de tiempos, actividades, gestos, etc. Es decir, la disciplina logra penetrar en los cuerpos para que sean atravesados por el orden.
} 
entre el adentro y el afuera. Por lo tanto, la Casa Verde (microcosmos) es Itaguaí (macrocosmos); el adentro es el afuera. Itaguaí es extensión de la locura o extensión del universo conquistado por el alienista. De esta forma, la mirada clínica de Bacamarte controla todo el asilo, que ya no es solo la Casa Verde, sino todo Itaguaí:

Todo el tiempo que le sobraba de los problemas de la Casa Verde era poco para andar por la calle, o de casa en casa, conversando con las gentes sobre mil asuntos y acompañando sus palabras con una mirada que daba miedo a los más heroicos" (Machado de Assis, 1974, p. 43).

De pronto, todo el pueblo está encerrado en esa mirada y en el miedo que provoca y que hace del espacio un lugar controlado sistemáticamente. ${ }^{17}$ Cuando esto ocurre, el pueblo le reclama al Ayuntamiento. La instancia normativa defiende a la científica, rechazando la petición del pueblo: “El ayuntamiento rehusó aceptarla, declarando que la Casa Verde era una institución pública, y que la Ciencia no podía ser corregida por votación administrativa y menos aún por agitaciones callejeras” (Machado de Assis, 1974, p. 67). Aquí se puede observar que, frente al pueblo, la instancia normativa acepta que la ciencia es intocable. No admite corrección de forma legal (votaciones administrativas) y mucho menos de forma ilegal (agitaciones callejeras). El reconocimiento a la instancia psiquiátrica es absoluto: no puede ser limitada por las leyes, lo que caracteriza precisamente al despotismo.

En efecto, en esta convergencia de la medicina mental y el proyecto político, jurídico, social y moral, la psiquiatría liga su destino al de la institución totalitaria (Castel, 2009, p. 58). Ya desde el Tratado de Pinel es posible ver una "reforma administrativa", como

${ }^{17}$ El control y dominio de Bacamarte se asemejan al Panóptico de Bentham, cuya estructura permite observar a todos los prisioneros, de ahí que para Michel Foucault (2008) es símbolo del auge del poder de la disciplina. Al mismo tiempo, para algunos, el Panóptico es metáfora del régimen dictatorial. A propósito, ver el trabajo de Scherman (2003). 
él mismo la llama, basada en un concepto de orden que va a facilitar la represión de cualquier intento de sublevación ante el poder psiquiátrico:

Fui conducido, como consecuencia de este espíritu de orden, a determinar las divisiones de la alienación en sus distintas especies, fundadas en observaciones numerosas y mejor constatadas. Esta distribución metódica tiene además una preciosa ventaja para establecer un orden constante en el servicio de los hospicios y contribuir al restablecimiento de los alienados (Pinel, 1809, citado en Castel, 2009, p. 70).

Según Castel, esta idea de orden de Pinel es la que alimenta todo el movimiento alienista. Para Pinel, esta disposición permitirá controlar enteramente a los alienados, desde la "conformidad de gustos e inclinaciones", hasta su "estado de calma o efervescencia" que facilitará el alejamiento de "todas las semillas de disensión y de perturbación” (Castel, 2009, p. 70). De ahí la propuesta de Castel de evidenciar esta relación entre psiquiatría y absolutismo político, pues la psiquiatría propone "una instrumentalización del poder absoluto que vuelve eficaz y racional su ejercicio" (Castel, 2009, p. 75).

Para Castel, hay una continuidad entre las instituciones de asistencia del Antiguo Régimen y las instituciones psiquiátricas. La diferencia entre ellas consiste en que la psiquiatría logra resolver una "aporía sobre la que se apuntalaba la vieja institución totalitaria" (Castel, 2009, p. 74). El sociólogo francés explica que, en el antiguo sistema, cuando se capturaba a los mendigos o maleantes, existían a menudo sublevaciones del pueblo, pues la captura y el encierro provocaban emociones entre la gente. La sublevación se debía, en el fondo, a un enfrentamiento político ante la "violencia del ejercicio del poder (...) que suscitaba la rebelión de las víctimas” (Castel, 2009, p. 74). 
Asimismo, las medidas disciplinarias aplicadas en los hospitales y en los depósitos de mendicidad eran todavía más dudosas: las medidas de los guardias, a los ojos del pueblo, eran vistas como sadismo y a esto respondía precisamente la rebelión de los reclusos. Castel compara la administración de estas instituciones con la de gobiernos despóticos y plantea que ambas fracasan en conseguir un "régimen regular de coacciones" (Castel, 2009, p. 75).

Sin embargo, con la institución psiquiátrica, la intervención, según su propia enunciación, es médica, no política (en apariencia), y el médico encierra a los alienados por "su propio bien" (tema de la filantropía). Así se justifica el encierro y, al mismo tiempo, se desmovilizan las reacciones populares frente al mantenimiento del orden (Castel, 2009, p. 75). En el asilo psiquiátrico, se justifica plenamente el "doble juego de la institución totalitaria: neutralizar y reeducar”. Ahí se realiza la síntesis perfecta entre saber y poder en la "figura moderna del filósofo-rey que es el médico-jefe" como si se tratara de una "pequeña república platónica" (Castel, 2009, p. 76).

Esto se problematiza en el relato cuando ocurre la revolución en Itaguaí. Un personaje aparentemente insignificante se alza como el líder de la revuelta en contra del “despotismo científico” de Bacamarte: el barbero, Porfirio (Machado de Assis, 1974, p. 67). Este personaje intenta derrocarlo denunciando su "afán de lucro" (Machado de Assis, 1974, p. 67), lo que develaría la corrupción de la institución psiquiátrica. Sin embargo, el presidente del Ayuntamiento le informa que no hay tal afán de lucro en el alienista y la prueba es que había renunciado al "estipendio" y a los "honorarios de las familias de los enfermos" cuando hacía experimentos de "alto valor psicológico" (Machado de Assis, 1974, p. 68). Esto calma los ánimos: 
La noticia de este gesto tan noble, tan puro, aplacó el ánimo de los rebeldes. Seguramente el alienista podía estar en un error, pero ningún interés ajeno a la Ciencia le instigaba; y para demostrar su error es necesario algo más que alborotos y clamores (Machado de Assis, 1974, p. 68).

La voz narrativa adquiere nuevamente un tono irónico, que claramente ridiculiza la ingenuidad del pueblo. Pone en evidencia que la institución psiquiátrica, en este enfrentamiento gana terreno, en la medida en que se percibe como "buena" o desinteresada. En apariencia, el gesto de desprendimiento pecuniario parece evidenciar que el interés de Bacamarte no es político, sino que está por encima de lo material: está en el lugar de la ciencia. Es la intervención de la medicina la que le otorga esta máscara aparentemente filantrópica al naciente alienismo (Castel, 2009, p. 75).

Luego, la Casa Verde se convierte en la "Bastilla de la razón humana" (Machado de Assis, 1974, p. 68), imagen que alude simbólicamente al triunfo de la Revolución francesa, y que va a funcionar como intertexto en el relato, el cual será parodiado y ridiculizado en la voz narrativa.

La toma de la Bastilla representa la derrota "del viejo orden monárquico y semifeudal en el continente europeo" (Montero, 2008, p. 54). Significó un cambio radical que le otorgó poder al pueblo por primera vez en la historia europea. Fue una victoria contra el despotismo. Además, según Álvaro Montero, la fecha de la Toma de la Bastilla se convierte en una "fecha universal para los pueblos que resuelven tomar las decisiones políticas en sus propias manos" (2008, p. 54).

La revolución de Itaguaí es parodia de la Revolución francesa en la medida en que es posible ver en ella la lógica del mundo al revés, por el hecho de que esta "Bastilla de la razón humana" - contrario a la parisina- nunca es tomada. Cuando triunfa la revolución 
en Itaguaí, en realidad fracasa, pues la Bastilla permanece intacta y, gracias al nuevo poder del barbero, conserva todo su poder.

Castel plantea que la psiquiatría perfecciona la relación de soberanía de la vieja institución totalitaria (2009, p. 74), es decir, perfecciona su capacidad de dominar y de controlar. De esta forma, en Itaguaí, esta versión de la Bastilla es una versión mejorada. Es superior a la vieja institución totalitaria representada por la Bastilla francesa, en cuanto a su capacidad de ejercer el poder sobre los cuerpos, pues como se ha explicado aquí, la violencia que ejerce se hace en nombre de la ciencia y por el bien de los sujetos.

En el discurso que pronuncia cuando el pueblo llega a tomarlo preso, el alienista consolida esta relación de "médico-jefe", versión moderna del "filósofo rey":

La Ciencia es algo muy serio, y merece ser tratada con seriedad. No doy razón de mis actos de alienista a nadie salvo a los Maestros y a Dios. Si queréis reformar la administración de la Casa Verde estoy dispuesto a oíros; pero si exigís que me niegue a mí mismo, no ganaréis nada. Podría invitar a uno de vosotros, en representación de todos, a que me acompañe a visitar a los locos recluidos; pero no lo hago porque sería daros cuenta de mi sistema, lo que no haré ni a conservadores ni a rebeldes (Machado de assis, 1974, p. 74).

La ciencia lo coloca por encima de la muchedumbre y lo eleva a una especie de dios. Su intervención deja de ser política y, en consecuencia, logra desmovilizar las reacciones populares: "Esto dijo el alienista y la multitud quedó atónita; estaba claro que no esperaba tanta energía y menos aún, tal seriedad” (Machado de Assi, 1974, p. 74).

Sin embargo, al final triunfa la revolución del pueblo, pero, curiosamente, la turba liderada por el barbero no se ocupa de la "Bastilla de la razón humana", sino de la institución normativa: el Ayuntamiento, cuyos concejales se rinden y son apresados. El 
barbero obtiene lo que anhelaba: poder. Así, asume el gobierno y se hace llamar "Protector de la Villa en nombre de Su Majestad y del pueblo" (Machado de assis, 1974, p. 80).

Esta revolución olvida su propósito inicial: derribar la Casa Verde y con ella la opresión del despotismo alienista. ${ }^{18}$ Este olvido retrata a un pueblo incapaz de detener la tiranía de esta nueva Bastilla, indestructible, pues se mueve a través de mecanismos ante los cuales parece imposible rebelarse. La tiranía de la nueva institución totalitaria -el nosocomio- continúa en Itaguaí, luego de la revolución y en medio de la debacle social. Porfirio, el nuevo "Protector" de Itaguaí, se adueña del Ayuntamiento, pero muy pronto comprende que necesita del alienista para consagrarse en su poder. ${ }^{19}$ De tal forma, va a la Casa Verde y reconoce ante el alienista la superioridad de la psiquiatría:

La generosa revolución que ayer derribó un Ayuntamiento despreciado y corrupto, pidió a gritos el arrasamiento de la Casa Verde; pero, ¿puede caber en el ánimo del gobierno eliminar la locura? No. Y si el gobierno no la puede eliminar, ¿está al menos capacitado para discriminarla, para reconocerla? Tampoco. Es asunto de la Ciencia (Machado de Assis, 1974, p. 88).

En el discurso del Barbero queda claramente demostrada la superioridad de la ciencia, pues ella da prueba de "su realeza”, de "su soberanía, su poder, su saber" (Foucault, 2007, p. 119). La instancia normativa (la del gobierno y las leyes) debe reconocer que es incapaz de ocuparse del problema de la locura. Sin embargo, a pesar de esta superioridad, sigue existiendo una connivencia entre ambas instituciones: "Luego, en asunto tan delicado, el gobierno no puede, no quiere prescindir de la cooperación de

\footnotetext{
${ }^{18}$ Este olvido es importante, pues evidencia el carácter carnavalesco de la trama.

${ }^{19}$ Ya el padre Lopes había rechazado colaborar con el nuevo gobierno del Barbero y esto pudo haber sido la primera señal que le indica al Barbero que necesita del alienista para tener aliados poderosos para controlar al pueblo.
} 
Vuestra Señoría. Lo que le pide es que de alguna manera demos alguna satisfacción al pueblo. Unámonos y el pueblo sabrá obedecer” (Machado de Assis, 1974, p. 88).

Finalmente, se hace clara la intención de la institución normativa: controlar a la población a través del orden. Si bien en un principio el pueblo le sirvió al Barbero para apoderarse del Ayuntamiento -que no de la Casa Verde- ahora reconoce que solo controlando al pueblo y sujetándolo en el orden podrá mantener su poder. El pueblo que luchaba por su libertad, en realidad celebra en la figura de este nuevo jefe la misma perpetuación de su encierro.

\section{Reflexiones finales}

En el texto machadiano es posible percibir el relato alegórico de la génesis de la psiquiatría, un recorrido por el nacimiento de la institución psiquiátrica y de los saberes que la constituyen. Tal senda parte de la antesala del encierro, presente en las reflexiones de Foucault (1972) en Histoire de la folie, momento determinante que va a marcar históricamente el rumbo que tomará la práctica psiquiátrica. El elemento definitivo para su surgimiento es el hecho de que llena un vacío de la instancia normativa, vacío que Bacamarte, en la novela, se encargará de denunciar y solucionar a través del advenimiento del alienismo. De tal forma, es posible ver cómo se crea a este nuevo sujeto social, el loco, un ser marcado por su condición de enfermo y, por ende, destinado a la exclusión y a la medicalización de su vida. Su creación supone la necesidad de una institución misericordiosa ante su sufrimiento y su estado de indefensión. La psiquiatría adquiere rasgos paternalistas que le dan un poder inmenso a esta institución, pues logra amalgamar el saber científico con la función filantrópica. 
La compasión no es más que una metáfora de la ley. Se encargará de perpetuar el funcionamiento de las regulaciones sociales encargadas de controlar a la población, que están amparadas por la instancia jurídica. En El alienista hay, sin embargo, un enfrentamiento de poderes, el normativo y el de la ciencia. La ciencia triunfa en la medida en que con la creación de la Casa Verde surge un nuevo universo, cuyo orden reposa en una nueva teología: ya no gobierna el dios cristiano, sino el dios de la ciencia. Por este motivo, Bacamarte está por encima de cualquier poder, al representar a su dios. En este nuevo universo el gobierno temporal, el jurídico-administrativo, debe someterse. En el relato, el poder de la psiquiatría triunfa sobre la instancia normativa.

En El Alienista se retrata el perfeccionamiento de las técnicas del poder del Antiguo Régimen, que, como lo indica Castel, se asemeja por su accionar a la lógica de los gobiernos tiranos; en cambio, la institución psiquiátrica, si bien se sirve del despotismo, tiene la capacidad de contener las reacciones de subversión a través de mecanismos de control, disfrazados de filantropía, y a través de la instancia médica, que surge para el supuesto bien de los enfermos. La institución psiquiátrica, encarnada en la Casa Verde, perfecciona la relación de soberanía que establecía la del Antiguo Régimen con la población.

Queda demostrado en el análisis del relato el planteamiento de Foucault: la institución psiquiátrica se consolida. Su función va a ser precisamente "proteger" a la sociedad frente a lo que amenace el orden. De esta forma, y una vez superados los obstáculos, Simón Bacamarte obtiene el poder absoluto. La psiquiatría logra lo que la institución totalitaria del Antiguo Régimen no logra. En nombre de la ciencia, se le permite dominar a sus anchas y ejercer la violencia represiva libremente. Más aún, gracias al poder de la ciencia, esta práctica llega a ser percibida como un acto bueno y 
desinteresado. A diferencia de la Bastilla de la Revolución francesa, esta Bastilla de Itaguaí es intocable. De tal forma, se parodia la Revolución francesa, pues en Itaguaí el triunfo del pueblo supone, en realidad, una derrota. El poder de las masas que surge con la revolución es, al final, una nueva forma de sumisión.

El poder deificado del alienista confirma su superioridad frente a la instancia normativa. De esta forma, el naciente alienismo da prueba de su dominio, al ser el único saber que puede identificar la locura. Su mirada es sacralizada, en la medida en que advierte lo oculto, aquello que nadie más parece advertir, el peligro, la falla, la anormalidad.

\section{Referencias bibliográficas}

Bal, M. (1998). Teoría de la narrativa (una introducción a la narratología). Madrid, España: Cátedra.

Bravo, L. (2008). Machado de Assis: estilo y estilete. Revista de cultura Agulha, (62). Recuperado de http://www.jornaldepoesia.jor.br/ag62assis.htm

Castel, R. (2009). El orden psiquiátrico. La edad de oro del alienismo. Buenos Aires, Argentina: Nueva Visión.

Colonna, V. (2004). Autofiction et autres mythomanies littéraires. Paris, Francia: Éditions Tristram.

Di Munno, A. (2008). A narrativa breve de Machado de Assis. Revista Electrônica do Instituto de Humanidades, VI(XXVII), Out-Dez.

Flores, M. (2007). La construcción cultural de la locura femenina en Costa Rica (1890-1910). San José: Edictorial UCR.

Foucault, M. (1972). Histoire de la folie à l'âge classique. Francia: Editions Gallimard. 
Foucault, M. (2003). Le pouvoir psychiatrique. Cours au Collège de France. 1973-1974. Francia: Seul Gallimard.

Foucault, M. (2007). Los anormales. Curso en el Collège de France (1974-1975). Argentina: Fondo de Cultura Económica.

Foucault, M. (2008). Vigilar y Castigar. Nacimiento de la prisión. México: Siglo XXI Editores.

Genette, G. (1972). Figures III. Paris, Francia: Seuil.

Gros, F. (2000). Foucault y la locura. Buenos Aires, Argentina: Ediciones Nueva Visión.

Machado de Assis, J. M. (1974). El alienista. Barcelona, España: Tusquets Editores.

Montero Mejía, Á. (2008). Actualidad de la independencia. Comunicación, 17(002), 53-61.

Moreira, A. C. G., y Berlinck, M. T. (2003). Mania de saber: ironia e melancolía em O alienista, de Machado de Assis. Revista Latinoamericana de psicopatología Fundamental, VI(2), $99-113$

Oliveira, Adriane. (2006). O Alienista: ou a ciência como religião. En Joao Cesar Rocha (Comp.), A Roda de Machado de Assis: ficciao, crónica e critica (pp. 333-353). Chapecó, Brasil: Argos.

Real Academia Española. (s. f.). Ayuntamiento. En Diccionario de la lengua española (23. ${ }^{\text {a }}$ edición). Recuperado de https://dle.rae.es/ayuntamiento

Scherman, J. (2003). La parodia del poder. Carpentier y García Márquez: desafiando el mito sobre el dictador latinoamericano. Chile: Editorial Cuarto Propio.

\section{@ $\odot \Theta \Theta$}

Esta obra está bajo una licencia de Creative Commons Reconocimiento-NoComercial- 